University of Nebraska - Lincoln

DigitalCommons@University of Nebraska - Lincoln

\title{
Clinical Effects and Antivenom Use for Snake Bite Victims Treated at Three US Hospitals in Afghanistan
}

\author{
Jason D. Heiner \\ University of Washington - Seattle Campus, jheiner@uw.edu \\ Vikhyat S. Bebarta \\ San Antonio Military Medical Center \\ Shawn M. Varney \\ San Antonio Military Medical Center \\ Jason D. Bothwell \\ Madigan Army Medical Center \\ Aaron J. Cronin \\ Womack Army Medical Center
}

Follow this and additional works at: https://digitalcommons.unl.edu/usarmyresearch

Heiner, Jason D.; Bebarta, Vikhyat S.; Varney, Shawn M.; Bothwell, Jason D.; and Cronin, Aaron J., "Clinical Effects and Antivenom Use for Snake Bite Victims Treated at Three US Hospitals in Afghanistan" (2013). US Army Research. 198.

https://digitalcommons.unl.edu/usarmyresearch/198

This Article is brought to you for free and open access by the U.S. Department of Defense at DigitalCommons@University of Nebraska - Lincoln. It has been accepted for inclusion in US Army Research by an authorized administrator of DigitalCommons@University of Nebraska - Lincoln. 


\title{
Clinical Effects and Antivenom Use for Snake Bite Victims Treated at Three US Hospitals in Afghanistan
}

\author{
Jason D. Heiner, MD; Vikhyat S. Bebarta, MD; Shawn M. Varney, MD; Jason D. Bothwell, MD; \\ Aaron J. Cronin, PA-C \\ From the University of Washington, Seattle, WA (Dr Heiner); the San Antonio Military Medical Center, Fort Sam Houston, TX (Drs Heiner, \\ Bebarta, and Varney); the Madigan Army Medical Center, Joint Base Lewis-McCord, WA (Dr Bothwell); and the Womack Army Medical Center, \\ Fort Bragg, NC (Mr Cronin).
}

Objective.-Annually, more than 100,000 US and international military and civilian personnel work in Afghanistan within terrain harboring venomous snakes. Current literature insufficiently supports Afghan antivenom treatment and stocking guidelines. We report the clinical course and treatments for snakebite victims presenting to US military hospitals in Afghanistan.

Methods.-All snakebite victims presenting to 3 US military emergency departments between July 2010 and August 2011 in northern and southern Afghanistan were examined via chart review. Case information included patient demographics, snake description, bite details and complications, laboratory results, antivenom use and adverse effects, procedures performed, and hospital course.

Results.-Of 17 cases, median patient age was 20 years (interquartile range [IQR], 12-30), 16 were male, and $82 \%$ were Afghans. All bites were to an extremity, and median time to care was 2.8 hours (IQR, 2-5.8). On arrival, 8 had tachycardia and none had hypotension or hypoxia. A viper was implicated in 5 cases. Ten cases received at least 1 dose of polyvalent antivenom, most commonly for coagulopathy, without adverse effects. Six received additional antivenom, 6 had an international normalized ratio (INR) $>10$, and none developed delayed coagulopathy. Three received blood transfusions. Hospital stay ranged from 1 to 4 days. None required vasopressors, fasciotomy, or other surgery, and none died. All had resolution of marked coagulopathies and improved swelling and pain on discharge.

Conclusions.-We report the largest series of snake envenomations treated by US physicians in Afghanistan. Antivenom was tolerated well with improvement of coagulopathy and symptoms. All patients survived with minimal advanced interventions other than blood transfusion.

Key words: snake envenomation, snake antivenom, Afghanistan

\section{Introduction}

The terrain of Afghanistan is inhabited by several venomous snakes with the potential to produce a variety of toxic effects including neurotoxicity, coagulopathies, and tissue necrosis: these include vipers (such as the

Presented at the 2012 GSACEP (Government Services Chapter of the American College of Emergency Physicians) Joint Services Symposium Research Forum, April 2-5, 2012, Olympic Valley, CA, and at the American College of Emergency Physicians (ACEP) 2012 Scientific Assembly, October 8, 2012, Denver, CO.

Disclaimer: The views expressed herein are solely those of the authors and do not represent the official views or policies of the US Government, Department of Defense, US Air Force, or US Army.

Corresponding author: Jason D. Heiner, MD, Division of Emergency Medicine, University of Washington Medical Center, 1959 NE Pacific St, Box 356123, Seattle, WA 98195 (e-mail: jheiner@uw.edu). saw-scaled viper, Echis carinatus) and the Oxus cobra (Naja oxiana). ${ }^{1-3}$ Although nearby countries such as Pakistan and India are reported by the World Health Organization to possess the largest annual snakebite mortalities in the world with a combined estimated annual snakebite mortality of up to 70,000 deaths per year, little is known about the burden of Afghan snake envenomations. $^{2-6}$ In addition to the indigenous population, each year more than 100,000 US and international civilians and military service members presently work in Afghanistan and are at risk for this environmental hazard.

Although snake envenomations occur continually during warm weather in Afghanistan, little information is available about these encounters and their subsequent medical treatment. To date the most comprehensive 
report is a voluntary, cross-sectional survey of 390 US military service members with primary duty assignment to Afghanistan, which was administered after they had departed the country. ${ }^{6}$ Although this study revealed 7 self-reported Afghanistan snake encounters and an increased risk of snakebite in Afghanistan compared with Iraq, no questions relating to clinical visits associated with these encounters were asked. ${ }^{6}$ Modern US military hospital facilities in Afghanistan frequently possess emergency departments (EDs) with emergency physicians, access to expert toxicology consultation, and available polyvalent snake antivenoms. However, the paucity of published reports of patients treated in these facilities for Afghan snakebites is insufficient to support guidance on hospital antivenom treatment and stocking guidelines. In this investigation we sought to report the clinical effects and treatments recorded for a series of snakebite victims presenting to 3 US military hospital EDs in Afghanistan.

\section{Methods}

All available medical records of all snakebite victims treated at 3 US military hospital EDs in Afghanistan between July 2010 and August 2011 were retrospectively reviewed. Site hospitals functioned as highvolume regional referral centers and were located in northwest (Herat Province), northeast (Parwan Province), and southern (Helmand Province) regions of the country and represented the geographic variety of the Afghan terrain. Patients (including international military coalition forces and local Afghan individuals) either primarily presented to or were transferred to their respective EDs for medical care. The diagnosis of snakebite was established by the emergency physician at the receiving facility. All 3 sites had access to expert toxicology consultation either at their respective hospitals or via telephone consultation. Although existing treatment guidelines included specific recommendations regarding symptoms such as progressive local edema or pain, coagulopathy, or marked systemic effects (such as hypotension or anaphylaxis), the decision to give antivenom was at the discretion of the treating ED physician, and antivenom products were not standardized across facilities.

Emergency physicians used a standardized data collection tool to extract available case information including patient demographics; snake species (if known); bite details including anatomic site, time to ED care, and clinical finding at the site noted during hospitalization; laboratory results; details of antivenom use including type, doses given, and noted adverse effects; and notable hospital course details including blood product transfusion, vasopressor use, and surgical procedures performed. Identification of the offending snake was generally by patient report with the assistance of zoological photographs of known Afghanistan snakes. Missing or unavailable data were noted as "unknown," and compiled data were analyzed using descriptive statistics. Institutional review board approval was received for this retrospective analysis of clinical cases.

\section{Results}

A total of 17 snakebite cases were available and included for data abstraction. Snakebite victims presented to site EDs between the months of March and August of the study period. Case distribution was 5 (29\%) from Herat Province, 4 (24\%) from Parwan Province, and 8 (47\%) from Helmand Province. Median reported patient age was 20 years (interquartile range [IQR], 12-30 years; range, 7-69 years). Sixteen patients were male (94\%), and most (82\%) were local Afghans. Two were enlisted American military service members (US Army and US Marine Corps). All bites were to an extremity, including finger or hand (6\%), arm (18\%), foot or ankle (47\%), and leg $(29 \%)$, and all were reported as legitimate in nature after accidental contact. Pseudocerastes persicus and E carinatus (multisquamatus or sochureki) was implicated in 5 cases, $N$ oxiana was identified by the patient in 1 case, and the remaining offending snake identities were uncertain.

Median time from bite to ED care was 2.8 hours (IQR, 2-5.8 hours; range, 30 minutes to 24 hours). On ED arrival 8 patients had tachycardia (heart rate $>100$ beats/min), and none had hypotension (systolic blood pressure ranged from 104 to $168 \mathrm{~mm} \mathrm{Hg}$ ) or hypoxia $\left(\mathrm{SpO}_{2}\right.$ ranged from $97 \%$ to $\left.100 \%\right)$. Reported laboratory values revealed a range of hematologic disturbances (Table). Nine $(53 \%)$ patients were found to have a leukocytosis (white blood cell count $>10 \times 10^{9} / \mathrm{L}$ ) on arrival. Six patients had an international normalized ratio $($ INR) $>10$, and 10 patients were treated with at least 1 dose of intravenous polyvalent antivenom (Razi Vaccine \& Serum Research Institute, Iran; or Favirept, Sanofi Pasteur SA, France), most commonly for a persistent elevated INR. One patient who reported envenomation by $N$ oxiana received antivenom for an INR $>10$ and painful extremity swelling. Those patients who received an additional administration of antivenom did so an average of 3.5 hours after the first dose (range, 2.5-6 hours). No anaphylaxis, serum sickness, or other adverse effects of antivenom treatment were noted. No patients developed delayed-onset coagulopathy after ED presentation. Three envenomated 
Table. Selected case details of snake bites treated with antivenom at 3 US hospitals in Afghanistan

\begin{tabular}{|c|c|c|c|c|c|c|c|c|c|c|c|}
\hline Case No. & $\begin{array}{l}\text { Age } \\
(y)\end{array}$ & $\begin{array}{l}\text { Reported Snake } \\
\text { Identity }\end{array}$ & Time: Bite to ED $(h)$ & $\begin{array}{c}\text { Initial } H C T \\
(\%)\end{array}$ & $\begin{array}{l}\text { Initial Platelets } \\
\qquad\left(\times 10^{9} / \mathrm{L}\right)\end{array}$ & Initial INR & $\begin{array}{c}\text { Total AV } \\
\text { Doses }\end{array}$ & AV Type ${ }^{a}$ & $\begin{array}{c}\text { Final } \\
H C T(\%)\end{array}$ & $\begin{array}{l}\text { Final Platelets } \\
\qquad\left(\times 10^{9} / L\right)\end{array}$ & Final INR \\
\hline 1 & 13 & Unk & 6 & 39.3 & 331 & $>12^{b}$ & 1 & Razi & $32.9^{b, c}$ & 215 & 1 \\
\hline 2 & 60 & Unk & Unk & 4.0 & 272 & 1.0 & 0 & N/A & Unk & Unk & Unk \\
\hline 3 & 7 & Unk & 24 & $35.6^{b}$ & 314 & $1.4^{b}$ & 0 & N/A & $32.5^{b}$ & 310 & Unk \\
\hline 4 & 30 & Unk & 1 & 46.2 & 209 & 1.2 & 0 & N/A & Unk & Unk & Unk \\
\hline 5 & 20 & Unk & Unk & 43.4 & 161 & 1.2 & 1 & Razi & $48.3^{c}$ & 175 & 1.2 \\
\hline 6 & 19 & Unk & 3.5 & 43.5 & 360 & $1.6^{b}$ & 4 & Favirept & 48.5 & 304 & $1.4^{b}$ \\
\hline 7 & 49 & Unk & 0.5 & 38.4 & 217 & 1.1 & 0 & N/A & Unk & Unk & Unk \\
\hline 8 & 23 & Unk & 3 & 43.6 & $91^{b}$ & 1.1 & 0 & N/A & Unk & Unk & Unk \\
\hline 9 & 20 & Unk & 0.5 & Unk & Unk & Unk & 0 & N/A & Unk & Unk & Unk \\
\hline 10 & 7 & Echis & 18 & $29.3^{b}$ & 290 & $>10^{b}$ & 4 & Favirept & $30.2^{b, c}$ & 220 & 0.7 \\
\hline 11 & 12 & $\begin{array}{l}\text { Pseudocerastes } \\
\quad \text { or Echis }\end{array}$ & 2 & 44.7 & $62^{b}$ & $>10^{b}$ & 4 & Favirept & 39.7 & 203 & 1.2 \\
\hline 12 & 22 & Unk & 2 & 42.7 & 218 & 1.2 & 0 & N/A & Unk & Unk & $1.3^{b}$ \\
\hline 13 & 29 & $\begin{array}{l}\text { Pseudocerastes } \\
\quad \text { or Echis }\end{array}$ & Unk & 49.2 & 215 & $4.1^{b}$ & 4 & Favirept & 36.5 & 167 & 0.8 \\
\hline 14 & 6 & Pseudocerastes & 5 & $33.5^{b}$ & 242 & $>10^{b}$ & 4 & Favirept & $31.3^{b}$ & 332 & $1.6^{b}$ \\
\hline 15 & 69 & Naja oxiana & 2.5 & 40.4 & 183 & $>10$ & 4 & Favirept & 39.7 & 159 & $1.7^{b}$ \\
\hline 16 & 7 & Pseudocerastes & 12.5 & $32.1^{b}$ & $78^{b}$ & 1.0 & 1 & Favirept & $30.3^{b}$ & 251 & 1.0 \\
\hline 17 & 30 & Unk & 2 & 41.7 & 316 & $1.8^{b}$ & 3 & Favirept & 43.9 & 309 & 1.0 \\
\hline
\end{tabular}

$\mathrm{AV}$, antivenom; Echis, Echis carinatus multisquamatus or Echis carinatus sochureki; ED, emergency department; HCT, hematocrit; INR, international normalized ratio; N/A, not applicable; Pseudocerastes, Pseudocerastes persicus; Unk, unknown.

${ }^{a}$ Razi indicates Razi Vaccine \& Serum Research Institute, Iran; Favirep indicates Favirept, Sanofi Pasteur SA, France.

${ }^{b}$ Indicates abnormal laboratory values.

${ }^{c}$ Notes the final hematocrit of the 3 patients who were transfused packed red blood cells as part of their treatment. 
patients received transfusions of packed red blood cells for anemia.

The hospital length of stay for all patients ranged from 1 to 4 days. No patients required tracheal intubation, vasopressor support, or fasciotomy or other surgery, and none died. At hospital discharge, all patients had resolution of marked coagulopathies (Table), and all reported improved or resolved extremity swelling and pain at discharge.

\section{Discussion}

We report the largest case series of Afghan snake envenomations treated by US physicians. Similar to past studies of envenomations in the Middle East and Southwest Asia, incidents occurred in the spring and summer (mirroring both the poikilothermic nature of snakes and increased outdoor human activities during these months), and extremity injuries predominated. ${ }^{5-8}$ Unlike the existing survey of Afghan snakebites and reports of Israeli Defense Force and Saudi Arabia snakebite victims, our series included children and elders rather than only adults or soldiers. ${ }^{6-8}$ Similar to our investigation, these past reports revealed the low occurrence of death of those patients seeking treatment as well as the low occurrence of known adverse effects of antivenom treatment. $^{6-8}$

Congruent with the complex and sometimes unpredictable effects of venom, a variety of clinical and hematologic abnormalities were observed. Although severe pain, coagulopathy, and edema were described, marked improvement or resolution of these abnormalities was noted in concert with administration of polyvalent antivenom. In the United States, a similar association with clinical improvement and low incidence of immediate hypersensitivity reaction has been observed with Crotalidae polyvalent immune Fab therapy after crotaline snake envenomation. ${ }^{9}$ Additionally, fasciotomy, amputation, or other surgical procedures were avoided in this cohort of patients, as was the need for vasoactive medications. Two patients with severely elevated INR and anemia each received a single transfusion of packed red blood cells in addition to antivenom, but were hemodynamically stable, and required no further blood products. Overall, these findings lend support to current antivenom availability and practices of administration.

Four antivenoms were supplied to study site hospitals and were potentially available to treat snake bites in the region: Saudi Polyvalent Snake Antivenom (Saudi Arabia), Razi Polyvalent Snake Antivenin (Iran), Favirept Polyvalent Snake Antivenin (France), and Haffekine/VinsBio Polyvalent Antivenom (India). These antivenoms contain purified, equine-derived $\mathrm{F}(\mathrm{ab})_{2}$ fragments and are able to treat a variety of the most commonly encountered vipers and elapids (including cobras) in the region. By design, the Razi (Iranian) antivenom may have the broadest singleagent coverage of expected Afghan venomous snakes. In our case series, the reported single envenomation by $N$ oxiana behaved clinically similar to other symptomatic bites, resulting in extremity edema, erythema, pain, and coagulopathy and resolving with administration of Favirept Polyvalent Snake Antivenin. The effects of only 2 antivenoms were observed during the study period (Razi Polyvalent Snake Antivenin and Favirept Polyvalent Snake Antivenin); although the Razi antivenom has potentially broader regional envenomation coverage by design, including possible better coverage of Pseudocerastes, our evidence does not favor one of these regionally available antivenoms over the other.

Limitations to this investigation exist, which should be noted. Although data extraction was structured, the presence of source record variability and the investigation's retrospective nature restrict the degree of patient detail available for review, limit assurance of complete patient data, and did not promote uniformity of data. This report relies on the optimal management of these snakebite victims, and care may have differed between emergency and inpatient providers. Moreover, initial ED management was not standardized, and providers in this austere setting were often challenged by unfamiliarity with the effects of these local venomous snakes and accurate determination of comprehensive patient-specific factors for treatment in light of commonly significant cultural, language, and health literacy barriers of envenomated Afghan patients. Patient cofounders such as unknown or undocumented coexisting medical problems may affect the generalizability of these findings. The short patient follow-up (maximum 4 days of total hospitalization) does not eliminate the presence of late complications, including serum sickness-type reactions that could have been attributed to antivenom administration. Although most culprit snake identifications were by local Afghans with presumed familiarity with local wildlife, and identification was assisted by zoological photos, the accuracy of the implicated snake species is uncertain. Without more certain identification, stronger conclusions cannot be made regarding the relative effectiveness of the antivenoms used against particular snake species.

Snakebites and snake envenomations in Afghanistan affect the local and visiting international populations, and currently, care rendered by US physicians is a common occurrence. From this detailed case series, we infer that present management of such patients, including the use of regional polyvalent antivenom, appears to be both safe and effective with evidence of good patient 
outcomes for those who reach emergency hospital care. Future studies may seek to clarify physician-perceived indications for antivenom use and lengthen the period of follow-up for detection of delayed complications. As the global and Afghan burden of snake envenomations continues, forthcoming investigations may further the individual and regional care and management of this potentially deadly environmental encounter.

\section{References}

1. Lamb L, Ross DA, Lalloo DG, Green A, Morgan ER, Warrell DA. Management of venomous bites and stings in British Military Personnel deployed in Iraq, Afghanistan and Cyprus. J R Army Med Corps. 2008;154(4 suppl):2-40.

2. Kasturiratne A, Wickremasinghe AR, de Silva N, et al. The global burden of snakebite: a literature analysis and modelling based on regional estimates of envenoming and deaths. PLoS Med. 2008;5:e218.

3. Ismail M, Memish ZA. Venomous snakes of Saudi Arabia and the Middle East: a keynote for travellers. Int $J$ Antimicrob Agents. 2003;21:164-169.
4. World Health Organization. Rabies and Envenomings: A Neglected Public Health Issue. Report of a consultative meeting. Geneva, Switzerland: World Health Organization; 2007.

5. Simpson ID. The "worldwide shortage" of antisnake venom: is the only right answer "produce more" or is it also "use it smarter?" Wilderness Environ Med. 2008;19: 99-107.

6. Shiau DT, Sanders JW, Putnam SD, et al. Self-reported incidence of snake, spider, and scorpion encounters among deployed U.S. military in Iraq and Afghanistan. Mil Med. 2007;172:1099-1102.

7. Haviv J, Huerta M, Shpilberg O, Klement E, Ash N, Grotto I. Poisonous animal bites in the Israel Defense Forces. Public Health Rev. 1998;26:237-245.

8. Al-Durihim H, Al-Hussaini M, Bin Salih S, Hassan I, Harakati M, Al Hajjaj A. Snake bite envenomation: experience at King Abdulaziz Medical City, Riyadh. East Mediterr Health J. 2010;16:438-441.

9. Lavonas EJ, Kokko J, Schaeffer TH, Mlynarchek SL, Bogdan GM, Dart RC. Short-term outcomes after Fab antivenom therapy for severe crotaline snakebite. Ann Emerg Med. 2011;57:128-137. 